\title{
Establishing a nexus between executive functions and management efficacy of academic leaders
}

\author{
Bryan B. Gabatino, Bonimar T. Afalla \\ College of Teacher Education, Nueva Vizcaya State University, Philippines
}

\begin{tabular}{l} 
Article Info \\
\hline Article history: \\
Received Jan 14, 2021 \\
Revised Jun 25, 2021 \\
Accepted Jul 12, 2021 \\
\hline
\end{tabular}

\section{Keywords:}

Academic leaders

BRIEF-A

College deans

Executive functions

Management efficacy

Program chairs

\begin{abstract}
Executive functions enable an individual to initiate and stop actions, track and modify behavior, and plan imminent behavior when faced with specific tasks and circumstances. This study, therefore, identified a connection between the executive functions and management efficacy of academic leaders of a State University in the Philippines. The Behavior Rating Inventory of Executive Function-Adult Version was used in a correlation analysis to gauge the executive functions of academic leaders and a researcher-made questionnaire was administered to determine their management efficacy. The study was conducted using t-scores, means, and Pearson $r$. The stronger the potential of academic leaders to carry out their management skills, the more their emotional regulation leans towards the borderline. As academic leaders' management skills become remarkable, the more they are predisposed to functioning on their own initiative and can control their actions in the light of the circumstances. Further, when academic leaders normally conduct change, self-monitoring, initiation, planning/organization, and task monitoring functions, they exemplify outstanding performance in their communication skills, adaptability, interpersonal relationships, and initiative, and imagination. But when their working memory, cognitive control, inhibition, and arrangement of materials is at the borderline, better interpersonal relationships, decision-making and judgment, and initiative and imagination are achieved.
\end{abstract}

This is an open access article under the CC BY-SA license.

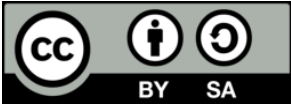

\section{Corresponding Author:}

Bonimar T. Afalla

College of Teacher Education

Nueva Vizcaya State University

Bayombong, Nueva Vizcaya, 3700 Philippines

Email: bonimarafallatominez0508@gmail.com; bonnafalla@nvsu.edu.ph

\section{INTRODUCTION}

Any organization exists to carry out a mission. It aims to boost its effectiveness by giving more thought to managerial success and helping leaders to get the best out of themselves and their teams [1]. In this demanding age of change and creativity, the education system of any community needs leaders who are not only productive and successful, but also capable of creating and sustaining an atmosphere conducive to the success of its stakeholders who work together to realize the institution's vision, purpose, and objectives [2].

The advancement of new educational thrusts and initiatives creates a growing strain on the part of academic leaders. Such stresses call on every leader to strengthen management skills, responsibilities, and functions to achieve the priorities and objectives of emerging educational growth [3]. In this light, leaders seem to have no other choice than to turn the university into a productive agent of transformation, calling this leader the organizational productivity manager. This transition involves the introduction of skills that are a 
crucial factor influencing the smooth execution of educational programs [4]. Therefore, in preparing, coordinating, directing, and managing the activities of the university to achieve leadership efficiency, it is the primary responsibility of academic leaders to perform managerial tasks [5].

The need to be aware of the evolving events taking place in global societies is related to the analysis of management skills, responsibilities, and functions concerning organizational effectiveness [6]. Academic leaders need to be vigilant all the time in this respect for progressing events that can have a huge impact on their lives [7]. Several of these recent developments include the sustainability of the global economy, advances in technology, diversity of the workforce, maximum quality control, ethics, and the problem and issues that any leader should not take lightly as they will impact education and training, administration, and supervision, and, research and evaluation [8].

Academic institutions are multifaceted areas of instability that are compromised by persistent demands for improvement [9] hence, academic leaders must recognize and cope with the need to handle adjustment and steadiness at the same time [10]. The regulatory focus theory suggests that when a governing match between a leader's supervisory styles and an organization's directing background is found, the forerunner will experience affirmative encouragement for variation and sustain it [11], [12]. As a result, academic leaders who recognize and integrate this concept into their leadership principles eventually discover that managerial modification is better applied, more exceedingly regarded, and ultimately more effective [13].

To thrive, all academic leaders must be capable of adapting to changing circumstances [14]. The capacity to respond to immediate salient stimuli by controlling instinctive responses such that expectations involving complex activities can be accomplished is described by cognitive psychologists as Executive Functions [15]. Executive functions are hypothesized as a collection of higher cognitive progressions that make humans focus on the possibilities, display self-control, and accomplish goal-directed actions effectively [16]-[18]. Impulse regulation, response inhibition, concentration, working memory, mental flexibility, planning, judgment, and decision-making are the tasks assumed to be involved in executive functions [19].

Productive expression of executive functions can be demarcated as intelligent behavior [20] and is important in daily life for proper development. Hence, researchers are becoming increasingly aware of how executive functions control individuals, whether at work or school. Damasio [21] and Grafman and Litvan [22], for example, have pointed out in their papers that individuals with differences in their executive functions have demonstrated a major weakening of their workability, school preferences, and interpersonal relations. Alvarez and Emory [23] expressed that these problems greatly affect an individual's facility to exert effort and work well intellectually and emotionally. Huizinga and Smidts [24] observed that concerns in executive functions can be expressed in driving action, in planning problems ahead, and in adjusting conduct to varying situations. Vitiello and Greenfield [25] concluded in their analysis that executive functions implicitly predicted learning practices (persistence, self-reliance, and motivation) and improvements in school readiness. Individuals with low executive functions normally have trouble communicating with others because they are predisposed to show offensive actions. Logue and Gould [15] emphasized that weak output on critical executive tasks may be attributed to deficiencies within some of the mental abilities of higher form which may be implicated in critical executive functions.

Executive functions are a collection of general-purpose control factors that underlie one's thinking and actions [26]. The general components of executive functions are outlined by Dendy [27] as working memory and recall; activation, enthusiasm and effort; managing emotions; internalizing language; recognizing problems, evaluating parts, reconstructing and assembling various tasks into new ideas; shifting and inhibiting; assembling and preparing ahead; and tracking. In like manner, Luu and Tucker [28] explained that executive functions exercise power over simple mental activities, including supervisory roles that must be carried out in cases where well-learned action is insufficient. Further, Aron [29] expressed that executive functions allow individuals to formulate objectives and plans; to recognize these objectives over time; to select and initiate action to accomplish the goal, and to track and change the activity until it is achieved. Furthermore, Huizinga and Smidts [24] shared their view that executive functions are cognitive mechanisms that are important for goal-oriented, productive, and adaptive actions, including the ability to think ahead; to subdue desires; to retain knowledge momentarily in mind, and to think openly. Additionally, Roth and associates [30] clarified that executive functions are higher-order cognitive skills interrelated with selfregulatory functions that coordinate, guide, and control cognitive skills, emotional responses, and overt actions. Moreover, Swami [31] opined that executive functions are essentially a brain management system that has the following activities: preparing, arranging, strategizing, paying attention to, remembering information, and managing time and space.

For successful adaptation and triumph in real academic scenarios, the executive functions of leaders are significant. Executive functions inspire academic leaders to undertake and fulfill their responsibilities and to persevere in the midst of challenges [32]. Since the world can be unpredictable, executive functions are 
essential to the human ability to discern the importance of unexpected situations and to make alternate plans rapidly when unusual incidents occur and interfere with usual routines [24], [33], [34]. In this way, executive functions contribute to work success and make it possible for academic leaders to manage daily events. Executive function is imperative for intricate or unusual tasks that entail unrelenting mindful considerations. Thus, playing a crucial role in daily behavior.

Centered on these viewpoints, this study was carried out to evaluate the relationship between the executive functions and management efficacy of academic leaders of a state university in the Philippines. Specifically, this research sought to: 1) Describe the level of executive functions of academic leaders in terms of inhibition, shift, emotional control, self-monitoring, initiation, working memory, planning/organization, task monitoring, and organization of materials; 2) Determine the level of management efficacy of academic leaders in terms of management skills, communication skills, interpersonal relations, decision-making and judgment, initiative and creativity, and adaptability as evaluated by themselves and their faculty members; and 3) Determine the significant relationship between the levels of executive functions and management efficacy among academic leaders.

\section{RESEARCH METHOD}

Using correlation analysis, this study subjectively selected 54 academic leaders, consisting of State University Deans and Program Chairs in the Cagayan Valley Region, Philippines. Following research ethics and when all consents were received, the researchers asked a psychometrician to perform a standardized test called BRIEF-A [35], [36] among research subjects to assess their executive functions or self-regulation daily. Table 1 presents the constructs and descriptions of BRIEF-A [24], [30].

In addition, the researchers administered a structured questionnaire among academic leaders and 191 randomly selected regular faculty members to assess the level of management efficacy of the subjects. Educational experts were asked to validate this instrument to test its internal accuracy and a Cronbach's alpha of 0.93 was derived, suggesting an outstanding degree of reliability. Table 2 reflects the dimensions and descriptions of management efficacy [37].

Mean and t-score were used to assess the level of executive functions; means were computed to represent the level of management efficacy; and Pearson $r$ was used to establish a significant relationship between the executive functions and efficacy of management of academic leaders.

Table 1. Constructs and descriptions of BRIEF-A

\begin{tabular}{lll}
\hline \multicolumn{1}{c}{ Constructs } & \multicolumn{1}{c}{ Descriptions } \\
\hline 1. Inhibition & The capacity to monitor urges and to restrain one's actions at the right time. \\
2. Shift & The flexibility to respond to actions that are adaptable to changing circumstances' demands. \\
3. Emotional control & The ability to modify feelings and emotions. \\
4. Self-Monitor & The potential to consider the impact with one's own actions on others. \\
5. Initiation & The ability to engage tasks and duties and autonomous production of proposals, techniques and \\
& reactions. \\
6. Working memory & The willingness to keep knowledge in perspective with a view to achieving an assignment. \\
7. Plan/Organize & The capacity to handle existing and future-oriented responsibilities. \\
8. Task monitor & The ability to track work and results either during or instantly after the completion of an activity. \\
9. Organization of materials & The ability to sustain systematized work, function and shared storage. \\
\hline
\end{tabular}

Table 2. Dimensions and descriptions of management efficacy

\begin{tabular}{lll}
\hline \multicolumn{1}{c}{ Dimensions } & \multicolumn{1}{c}{ Descriptions } \\
\hline 1. Management skills & The success in preparing, arranging, handling, and governing. \\
2. Communication skills & The extent to which there is accuracy in communication both verbally and in writing. \\
3. Interpersonal relations & The success in dealing with other leaders, subordinate, peers, and students \\
4. Decision-making and judgment & The efficiency of problem identification and the selection of effective action. \\
5. Initiative and creativity & $\begin{array}{l}\text { The willingness to take responsibility, come up with new ideas and cope with unexpected } \\
\text { circumstances at work. }\end{array}$ \\
6. Adaptability & The capacity for adjustment to cope. \\
\hline
\end{tabular}

\section{RESULTS AND DISCUSSION}

\subsection{Academic leaders' level of executive functions}

Table 3 reflects the overall level of executive functions of academic leaders in the areas of nine constructs such as inhibition, shift, emotional control, self-monitoring, initiation, working memory, planning/organization, task monitoring, and organization of materials. 
Table 3. Level of executive functions of academic leaders as measured by BRIEF-A

\begin{tabular}{|c|c|c|c|c|c|c|c|c|}
\hline \multirow[b]{2}{*}{ Executive function constructs } & \multicolumn{4}{|c|}{ College deans } & \multicolumn{4}{|c|}{ Program chairs } \\
\hline & $\begin{array}{c}\mathrm{C} 1 \\
\text { ts }\end{array}$ & $\begin{array}{c}\mathrm{C} 2 \\
\text { ts }\end{array}$ & Ots & QD & $\begin{array}{c}\mathrm{C} 1 \\
\text { ts }\end{array}$ & $\begin{array}{l}\mathrm{C} 2 \\
\mathrm{Ts}\end{array}$ & Ots & QD \\
\hline Inhibition & 54 & 53 & 53.5 & $\mathrm{~B}$ & 52 & 53 & 52.5 & $\mathrm{~B}$ \\
\hline Shift & 60 & 47 & 53.5 & B & 54 & 55 & 54.5 & B \\
\hline Emotional control & 52 & 51 & 51.5 & B & 51 & 51 & 51 & B \\
\hline 4. Self-monitoring & 51 & 47 & 49 & $\mathrm{~N}$ & 44 & 50 & 47 & $\mathrm{~N}$ \\
\hline 5. Initiation & 57 & 47 & 52 & B & 51 & 53 & 52 & B \\
\hline 6. Working memory & 46 & 45 & 45.5 & $\mathrm{~N}$ & 44 & 45 & 44.5 & $\mathrm{~N}$ \\
\hline 7. Planning/Organization & 54 & 46 & 50 & B & 49 & 48 & 48.5 & $\mathrm{~N}$ \\
\hline 8. Task monitoring & 53 & 53 & 53 & B & 55 & 53 & 54 & B \\
\hline 9. Organization of materials & 50 & 46 & 48 & $\mathrm{~N}$ & 48 & 49 & 48.5 & $\mathrm{~N}$ \\
\hline
\end{tabular}

C1: Campus 1; C2: Campus 2; ts: average t-score; Ots: overall t-score

$\mathrm{t}$-score range/qualitative description: 30-49/Normal (N); 50-64/Borderline (B); 65 and above/Clinically impaired (CI)

The academic leaders fall under the borderline category in inhibition, which means that they have a propensity to behave impulsively. Some possibilities could be difficult for them to avoid or act on their actions in an inappropriate period. This result confirms that emotional intelligence is one of the main competencies of the leaders. Leaders should be mindful of how their actions will affect the dynamics of their group and self-management should be practiced. In the case of academic leaders, this is the characteristic that needs to be changed by being vigilant about the remarks that they may make as inappropriate sensual remarks. They need to look at the choices they make that can lead to legal, financial, or social problems [38].

For shift construct, the academic leaders fall under the borderline category, which shows that they have no difficulty in shifting freely from one situation, operation, or component of a problem to another. To support, critical intelligence is a must for a leader by being able to interpret or evaluate knowledge for various circumstances. Creativity and adaptability are qualities that have the potential to impact successful or superior efficiency [39].

In emotional control, academic leaders at the study site fall into the borderline group, which indicates that they have trouble controlling their emotional reactions. There are chances that they may experience emotional outbursts from time to time. Emotional maturity is a must for academic leaders. Leaders should be aware of better tracking or acting on their emotions. Self-awareness and self-control are the qualities that leaders can possess [38], [39].

Academic leaders fall into the normal category in self-monitoring, which means that they keep track of their own actions and the effects of their actions on others. Since this construct is in the normal range, they can rely on this trait to control their desires and to become versatile in their thoughts and acts. Besides, effective behavioral control is expected to be a key to successful metacognitive problem-solving. It enables cognitive development to effectively direct constructive and systemic problem-solving and, more broadly, to facilitate effective self-regulation. McClelland and associates [40] clarified that self-esteem acts as a personal guiding mechanism that influences the motivation and actions of an individual, stressing that high or low self-esteem affects one 's performance. People who are extremely self-monitored appear to have low selfesteem, whereas people who otherwise appear to have high self-esteem.

For initiation, academic leaders fall under the borderline category which reveals that they show a tendency to succeed at a certain task but they experience difficulty in getting started. There are possibilities that they may struggle to initiate an operation or activity and spontaneously produce ideas, reactions, or problem-solving schemes. The cognitive intelligence states that leaders should have the expertise and experience to start a task or solve a problem in their domain [39].

In working memory, academic leaders fall under the normal category, which means that they have the capacity to consciously keep knowledge in mind to complete a mission or produce an answer. They have the capacity to carry out several operations, to carry out sequences of actions, or to obey complex instructions. If they are directed properly, they will effectively execute the programs assigned to them. Aron [41] clarified that working memory affects a person's performance. When impaired, it may lead to difficulties in reading comprehension, suppressing the activation of irrelevant knowledge, filtering, managerial and selfmonitoring abilities, and the retention of ideas. People with impaired working memory have difficulty using behavioral techniques that require memorization and retrieval of several procedures. On the other hand, Clark and associates [42] underscored that people with excellent working memory show exceptional efficiency in all tasks.

In planning/organization, the deans fall under the borderline category, while the program chairs fall under the normal category. Findings suggest that deans are more likely to have trouble predicting potential events, executing directives or strategies, and planning suitable steps ahead of time to carry out the tasks or 
activities of their counterparts. Deans can haphazardly tackle tasks or quickly absorb vast volumes of knowledge or action rather than their program chairs. Planning, as emphasized by Aron [29], plays a crucial role in management, helping to foresee potential challenges, and keeping management primed for possible solutions. It is also referred to as the primary management role because it provides the basis for everything else leaders need to do. It is referred to as a decision-making feature because it requires imaginative thinking and creativity that eventually contributes to the development of new approaches and the success of an organization.

In general, academic leaders fall under the borderline group in task monitoring. This represents their propensity to fail to notice or be conscious of one's own mistakes. Bull, Espy and Wiebe [43] clarified that most goal-directed tasks are time-based tasks on which time-scale scheduling, task-monitoring, and task interleaving take place. The integration of multiple priorities and deadlines involves a high level of cognitive control. Without this essential purpose, the company has no guidance, and leaders are set up to deal with mistakes, waste, and delays.

Academic leaders fall into the normal category in organization of materials, which means that they demonstrate organization in their daily environment in terms of the orderliness of work, living, storage, and space. Findings confirm Denckla's [44] core characteristics of executive functioning, which include intervention management, effortful and versatile organization, and strategic planning (anticipatory goaldirected preparedness to act), and material organization. She also stressed that there are skills that the leader should possess: initiate, maintain, inhibit, move. When these abilities are lacking, there is no question that individuals fail.

Inhibition, change, emotional regulation, and self-monitoring are the first four structures that capture the capacity to keep proper regulatory power about one's own actions and emotional experience. This is the behavioral regulation index (BRI) which includes an adequate suppression of perception and behavior, versatility in changing problem-solving sets, control of emotional reaction, and regulation of one's actions. Initiation, working memory, planning/structure, task control and content structure are the next cluster of constructs that describe the metacognition index (MI) [45]. This describes the capacity of individuals to initiate activities and produce problem-solving ideas, retain working memory, schedule and coordinate problem-solving methods, track progress and failure in problem-solving, and manage their own materials and environment [24]. Stamenova and Levine [46] suggested that executive functions are high-level capacities involved in regulating purpose-driven actions and affect more fundamental skills such as attention, memory, and motor skills. Also, Miyake and Friedman [47] emphasized that executive functions are a fundamental element of the capacity to self-control or self-regulate. Furthermore, Krasny-Pacini and associates [48] also shared their view that executive functions are interdependent components that include the ability to articulate objectives; to facilitate actions; to predict the effects of decisions; to manage and coordinate conduct; to track and adjust behavior to a specific task or material. Roth and associates [30] pointed out that executive functions also affect computational power by encouraging people to use approaches that can help them extract information, highlight the role of careful planning, and modify strategies and processes.

\subsection{Academic leaders' level of management efficacy}

Table 4 reflects the level of management efficacy of academic leaders along their management skills, communication skills, interpersonal relations, decision-making and judgment, initiative and creativity, and adaptability as evaluated by themselves and their subordinates.

Table 4. Overall level of management efficacy of academic leaders

\begin{tabular}{llrrrrrc}
\hline \multirow{2}{*}{ Dimensions } & \multicolumn{2}{c}{ Self-evaluation } & \multicolumn{2}{c}{ Teachers' evaluation } & \multirow{2}{*}{ Overall mean } & \multirow{2}{*}{ QD } \\
& & mean & QD & mean & QD & & VS \\
\hline 1. & Management skills & 4.13 & VS & 4.09 & VS & 4.11 & O \\
2. & Communication skills & 4.34 & $\mathrm{O}$ & 4.13 & $\mathrm{VS}$ & 4.23 & $\mathrm{O}$ \\
3. & Interpersonal relations & 4.54 & $\mathrm{O}$ & 4.13 & $\mathrm{VS}$ & 4.33 & $\mathrm{O}$ \\
4. & Decision-making and judgment & 4.42 & $\mathrm{O}$ & 4.08 & $\mathrm{VS}$ & 4.25 & $\mathrm{VS}$ \\
5. & Initiative and creativity & 4.25 & $\mathrm{O}$ & 4.12 & $\mathrm{VS}$ & 4.18 & $\mathrm{O}$ \\
6. & Adaptability & 4.29 & $\mathrm{O}$ & 4.11 & $\mathrm{VS}$ & 4.20 & \\
\hline
\end{tabular}

Academic leaders performed this management role quite successfully, which reflects the fact that they possessed the unique skills required to handle their own turfs effectively. They need these skills to understand how each part of their domains integrates and contributes to the ultimate purpose of the university. Academic leaders have been ranked outstanding in their communication skills, which indicate that they have carried out their management tasks with extremely high quality. This further indicates that the outstanding communication 
skills of academic leaders allow them to develop effective dealings. They assume that no one can fight, negotiate effectively, and excel in leading without decent contact. When contact is disrupted and hampered, the Entity as a whole suffers. When communication is structured, reliable, and necessary, the organization appears to be efficient.

Academic leaders have been considered to be excellent in their interpersonal relationships, which are the secret to achieving what they want to accomplish in the working world. Furthermore, as academic leaders, they need to create professional and friendly cooperation between their constituents to build unity, concern, and reverence for one another.

Academic leaders have been judged to be excellent in their decision-making and judgment, demonstrating their strong capacity to make fair judgments and to draw detailed conclusions to resolve administrative disputes and issues. Academic leaders have been judged to be very competitive in their initiative and innovation, showing that they have a strong capacity to demonstrate their own imagination and originality in resolving obstacles and unraveling institutional challenges.

Academic leaders were judged to be excellent in the performance of adaptability in leading their own departments, demonstrating that they could effectively fulfill new duties or roles in the midst of organizational changes and challenges.

Academic leaders are administrators who communicate directly with, order, and assess the performance of their subordinates. They are responsible for achieving the targets set by the top management. They invest more time in organizational management tasks [49]. Their functions can be highlighted as implementing operational strategies in line with the agency's policies and objectives. To make effective decisions, a person must also be able to predict the effect of each choice and decide which option is best suited to a specific situation [31]. Thus, a final possibility is made by any decision-making process. In the same way, Bakotić [50] stressed that leaders must have certain managerial skills that allow them to carry out their tasks successfully. In several cases, these skills are the organization's most important asset. The degree of development of the leader in-job segment would have a significant impact not only on the outstanding performance of the workers, but also on the success of the organization [51].

\subsection{Significant relationship between academic leaders' executive functions and management efficacy}

Table 5 shows the relationship between the constructs of executive functions and dimensions of management efficacy of academic leaders. Results reveal that each dimension of management efficacy has a significant relationship to the basic structure of executive functions. This means that the management performance of academic leaders is more likely to be related to their executive functions. Notice that items under executive functions are classified as negative statements which indicate that low performance in executive functions means that academic leaders are better-controlled daily.

Specifically, management skills provide the largest number of significant relationships with the development of executive functions. Dimensions such as self-monitoring, task monitoring, planning/organization, initiation, shifting, and inhibition indicate a negative relationship with management skills which indicates that, given the exceptional performance of academic leaders in their management skills, they appear to be normal in their executive functions along these lines.

On the other hand, emotional control has a positive relationship with this particular segment of work, which indicates that the greater the ability of academic leaders to exercise their management skills, the more their emotional control appears to be within the boundaries of their executive function. Management skills are those related to how all parts of the agency work together. They cover a wide range of activities, from articulating goals, policies, and procedures to developing strategies for managing the flow of organizational work and organizing a multitude of seemingly unrelated functions that allow it to operate as an integrated entity [2]. These skills are those relevant to the manager's efficacy in preparing, coordinating, managing, and governing, which allows them to process a large amount of knowledge on the internal and external environment of the company and to assess the consequences of this knowledge. In the same vein, Runco and Jaeger [52] argued that creativity described as the capacity to generate novel and valuable results can be represented by upgrading, adjusting, and inhibition. The capacity to track and add or remove working memory content can be useful when determining and replicating separate principles. Changing influential reactions and openness to more innovative thoughts can also lead to innovative reasoning [32]. 
Table 5. Relationship between the levels of executive functions and management efficacy of academic leaders

\begin{tabular}{|c|c|c|c|c|c|c|c|c|}
\hline \multirow{2}{*}{\multicolumn{3}{|c|}{ Executive function constructs }} & \multicolumn{6}{|c|}{ Management efficacy dimensions } \\
\hline & & & MS & $\mathrm{CS}$ & IR & DMJ & IC & A \\
\hline \multirow[t]{2}{*}{1.} & Inhibition & r-value & $-.11 *$ & -.20 & .10 & $.22 * *$ & .10 & .30 \\
\hline & & Sig & .04 & .64 & .06 & .00 & .80 & .63 \\
\hline \multirow[t]{2}{*}{2.} & Shift & r-value & $-.12 *$ & $-.20 * *$ & -.70 & -.10 & -.70 & -.10 \\
\hline & & Sig & .02 & .00 & .17 & .92 & .20 & .06 \\
\hline \multirow[t]{2}{*}{3.} & Emotional control & r-value & $.21^{* *}$ & .30 & -.30 & $.13 * *$ & $.18^{* *}$ & -.10 \\
\hline & & Sig & .00 & .55 & .59 & .01 & .00 & .83 \\
\hline \multirow[t]{2}{*}{4.} & Self-monitoring & r-value & $-.20 * *$ & $-.27 * *$ & $-.11 *$ & -.40 & $-.16^{* *}$ & $-.20 * *$ \\
\hline & & Sig & .00 & .00 & .04 & .47 & .00 & .00 \\
\hline \multirow[t]{2}{*}{5.} & Initiation & r-value & -.15 & $-.15^{* *}$ & .10 & .90 & $-.11 *$ & -.90 \\
\hline & & Sig & .00 & .00 & .81 & .09 & .04 & .10 \\
\hline \multirow[t]{2}{*}{6.} & Working memory & r-value & -.30 & -.00 & $.11^{*}$ & $.15^{* *}$ & .30 & -.10 \\
\hline & & Sig & .62 & .94 & .03 & .01 & .61 & .79 \\
\hline \multirow[t]{2}{*}{7.} & Planning/Organization & r-value & $-.16^{* *}$ & $-.17 * *$ & .10 & .60 & -.90 & -.70 \\
\hline & & Sig & .00 & .00 & .92 & .24 & .07 & .19 \\
\hline \multirow[t]{2}{*}{8.} & Task monitoring & r-value & $-.20 * *$ & $-.16^{* *}$ & .60 & .40 & -.50 & $-.11 *$ \\
\hline & & Sig & .00 & .00 & .28 & .48 & .38 & .04 \\
\hline \multirow[t]{2}{*}{9.} & Organization of materials & r-value & -.70 & -.80 & .70 & $.12 *$ & -.10 & -.50 \\
\hline & & Sig & .18 & .14 & .19 & .02 & .07 & .32 \\
\hline
\end{tabular}

significant at $.05 * *$ significant at .01

$\mathrm{MS}=$ Management skills; $\mathrm{CS}=\mathrm{Communication}$ skills; $\mathrm{R}=$ Interpersonal relations;

$\mathrm{DMJ}=$ decision making and judgment; $\mathrm{IC}=$ Initiative and creativity; $\mathrm{A}=$ Adaptability

Furthermore, inverse relationships were also evident within the following job segments and constructs: communication skills and shift, self-monitoring, initiation, planning/organization and task monitoring; interpersonal relationships and self-monitoring, initiative and imagination, and self-monitoring and initiation; and adaptability and self-monitoring and task monitoring. Results indicate that when academic leaders are natural in their executive roles over change, self-monitoring, initiation, planning/organization, and task monitoring, better communication skills, adaptability, interpersonal relationships, and initiative and imagination among academic leaders are guaranteed. These results corroborate the arguments of Mehra and associates [53] that high self-monitors carefully change their actions based on input from others. They manipulate their interpersonal experiences to give the most successful impression and achieve the desired effect. Low self-monitors are not concerned with the picture they are showing. Rather, they express their thoughts and feelings free, without attempting to manipulate the perceptions they make.

Besides, Oosterlaan and associates [54] found out that high self-monitors are well aware of the situational characteristics and what is and is not acceptable in a particular situation. Therefore, the action of such a person is essentially a particular circumstance. High self-monitoring is versatile and adaptable. They exhibit different actions from one situation to another. On the other hand, low self-monitors are less attentive and less worried about what is or is not acceptable. As a consequence, they will strive to act uniformly across relationships. Low self-monitors display no change from one case to another. Phillips and associates [19] shared their point of view that managerial regulatory systems are essential for improving thoughts and behavior, for decision making and problem-solving, for correcting and for executing new tasks. The removal of undesirable reactions, the change from one role to yet another, and the development of successful recovery strategies are amongst the nomenclature of executive functions. It was noted that successful self-regulation of institutions emerges whenever leaders can achieve both short and long-term desired goals across strategies that suit their strategic emphasis and those of their setting [13].

On the other hand, there were constructive relationships between the following dimensions and structures: interpersonal relationships and working memory; decision-making and judgment and emotional control, working memory, inhibition, and organization of materials; and initiative and creativity and emotional control. As academic leaders tend to be at the margin of their executive functions in terms of their working memory, emotional regulation, inhibition, material organization, there is a greater chance of achieving stronger interpersonal relationships, decision-making and judgment, and initiative and imagination. From a theoretical process, the decision-making practice could be seen as a constant cycle incorporated into contact with the environment while from a conceptual point of view, the identification of specific judgments involves the essence of decision-making and justification and the relativistic option that corresponds to it [55], [56]. At yet another stage, it could be seen as a problem-solving operation that concludes when a suitable result is obtained [57], [58]. Thus, decision-making is a logical or psychological mechanism that can be negative or positive and therefore can be founded on clear premises or implicit expectations [59]-[61]. 


\section{CONCLUSION}

College deans are average in their executive functions, along with their working memory, resources management, and self-monitoring. They did, however, show an executive function within the boundary in terms of inhibition, moving, emotional regulation, initiation, planning/organization, and task monitoring. On the other hand, program chairs are natural in their self-monitoring, working memory, planning/organizing, and establishing resources, but they have an executive function within the boundary in terms of inhibition, change, emotional regulation, initiation, and task monitoring.

Academic leaders have shown substantially better organizational skills and commitment and innovation than is typically required of them in carrying out their designations. However, they have consistently attained exceptionally high performance in terms of communication skills, interpersonal interactions, decision-making and judgment, and adaptability.

The stronger the willingness of academic leaders to carry out their management skills, the more their emotional regulation leans towards the borderline. Furthermore, when they surprisingly practice their management skills, they appear to be average in inhibition, moving, self-monitoring, initiation, planning/organization, and task monitoring. That is, as academic leaders' management skills reach a remarkable level, the more they are encouraged from functioning on their own initiative and can control their actions in the light of the circumstances. On the other hand, when the academic leaders' executive functions along with change, self-monitoring, initiation, planning/organization, and task monitoring functions become normal, they exemplify outstanding performance in their communication skills, adaptability, interpersonal relationships, and initiative and innovation. But when their working memory, emotional regulation, inhibition, and organization of materials are placed within the boundary, healthy interpersonal relationships, decision-making and judgment, and initiative and imagination are achieved.

With these conclusions, the researchers humbly forward the following: 1) Academic organizations can institutionalize the conduct of BRIEF-A to all approved designees to determine their suitability in their assigned positions; 2) A practical analysis of the success of academic leaders using a standardized framework can be required to better recognize their strengths and areas of improvement. Interventions can be planned and made available for this purpose; 3) Academic leaders may make greater efforts to further improve their management efficacy. They will be more successful leaders if they learn to be more mindful of how their actions and thoughts will influence their relationships with others, especially their subordinates; and 4) Future researchers may replicate this study to validate the findings and identify other potential attributes that may be correlated with management efficacy and executive functions.

\section{ACKNOWLEDGEMENTS}

The authors extend their gratitude to the Nueva Vizcaya State University, Philippines, for the permission granted in the conduct of this research.

\section{REFERENCES}

[1] W. W. Burke, Organization change: Theory and practice. Sage Publications, 2017.

[2] S. Tonidandel, P. W. Braddy, J. W. Fleenor, "Relative importance of managerial skills for predicting effectiveness," J. Manage. Psychol., vol 27, no. 6, pp. 636-655, 2012, doi: 10.1108/02683941211252464.

[3] C. Cláudia, Miguel A. Ferreira, and P. Matos, "Do general managerial skills spur innovation?" Management Science, vol. 65, no. 2, pp. 459-476, 2019.

[4] J. A. Grissom and S. Loeb, "Triangulating principal effectiveness: How perspectives of parents, teachers, and assistant principals identify the central importance of managerial skills," American Educational Research Journal, vol. 48, no. 5, pp. 1091-1123, 2011, doi: 10.3102/0002831211402663.

[5] J. de Oliveira, E. Escrivão, M. S. Nagano, A. S. Ferraudo, and D. Rosim, "What do small business owner-managers do? A managerial work perspective," Journal of Global Entrepreneurship Research, vol. 5, no. 1, pp. 1-21, 2015.

[6] W. A. Gentry, L. S. Harris, B. A. Baker, and J. B. Leslie, "Managerial skills: What has changed since the late 1980s," Leadership \& Organization Development Journal, vol. 29, no. 2, pp. 167-181, 2008, doi: $10.1108 / 01437730810852506$.

[7] T. Vilkinas, and R. K. Ladyshewsky, "Leadership behaviour and effectiveness of academic program directors in Australian universities," Educational Management Administration and Leadership, vol. 40, no. 1, pp. 109-126, 2012.

[8] H. Büyükgöze, "Understanding Effectiveness in School Administration: A Discourse Analysis," Acta Didactica Napocensia, vol. 9, no. 3, pp. 67-76, 2016.

[9] W. W. Burke, W. J. Trahant, and R. Koonce, Business climate shifts: Profiles of change makers. Routledge, 2000.

[10] A. M. Pettigrew, R. W. Woodman, and K. S. Cameron, "Studying organizational change and development: Challenges for future research," Academy of Management Journal, vol. 44, no. 4, pp. 697-713, 2001.

[11] E. T. Higgins, "Beyond pleasure and pain,” American Psychologist, vol. 52, no. 12, pp. 1280-1300, 1997. 
[12] E. T. Higgins, "Making a good decision: value from fit," American Psychologist, vol. 55, no. 11, pp. 1217-30, 2000 .

[13] A. Taylor-Bianco and J. Schermerhorn Jr, "Self-regulation, strategic leadership and paradox in organizational change," Journal of Organizational Change Management, Vol. 19, No. 4, pp. 457-470, 2006, doi: $10.1108 / 09534810610676662$.

[14] M. Ylvisaker and T. Feeney, "Executive functions, self-regulation, and learned optimism in paediatric rehabilitation: a review and implications for intervention," Pediatric Rehabilitation, vol. 5, no. 2, pp. 51-70, 2002.

[15] S. F. Logue and T. J. Gould, "The neural and genetic basis of executive function: attention, cognitive flexibility, and response inhibition," Pharmacology Biochemistry and Behavior, vol. 123, pp. 45-54, 2014.

[16] A. Baddeley, "The central executive: A concept and some misconceptions," Journal of the International Neuropsychological Society, vol. 4, no. 5, pp. 523-526, 1998.

[17] T. W. Robbins, "Dissociating executive functions of the prefrontal cortex," Philosophical Transactions of the Royal Society of London. Series B: Biological Sciences, vol. 351, no. 1346, pp. 1463-1471, 1996.

[18] D. T. Stuss, and M. P. Alexander, "Executive functions and the frontal lobes: a conceptual view," Psychological Research, vol. 63, no. 3-4, pp. 289-298, 2000, doi: 10.1007/s004269900007.

[19] L. H. Phillips, R. Bull, E. Adams, and L. Fraser, "Positive mood and executive function: Evidence from Stroop and fluency tasks," Emotion, vol. 2, no. 1, pp. 12-22, 2002, doi: 10.1037/1528-3542.2.1.12.

[20] J. Duncan, et al., "A neural basis for general intelligence," Science, vol. 289, no. 5478, pp. 457-460, 2000.

[21] A. R. Damasio, Descartes' error: Emotion, rationality and the human brain. Penguin Books, 1994.

[22] J. Grafman and I. Litvan, "Importance of deficits in executive functions," The Lancet, vol. 354, no. 9194, pp. 1921-1923, 1999.

[23] J. A. Alvarez and E. Emory, "Executive function and the frontal lobes: a meta-analytic review," Neuropsychology Review, vol. 16, no. 1, pp. 17-42, 2006, doi: 10.1007/s11065-006-9002-x.

[24] M. Huizinga and D. P. Smidts, "Age-related changes in executive function: A normative study with the Dutch version of the Behavior Rating Inventory of Executive Function (BRIEF)," Child Neuropsychology, vol. 17, no. 1, pp. 51-66, 2010, doi: 10.1080/09297049.2010.509715.

[25] V. E. Vitiello and D. B. Greenfield, "Executive functions and approaches to learning in predicting school readiness," Journal of Applied Developmental Psychology, vol. 53, pp. 1-9, 2017, doi: 10.1016/j.appdev.2017.08.004.

[26] N. P. Friedman and A. Miyake, "Unity and diversity of executive functions: Individual differences as a window on cognitive structure," Cortex, vol. 86, pp. 186-204, 2017, doi: 10.1016/j.cortex.2016.04.023.

[27] C. A. Z. Dendy, "Executive function," Chadd's Attention Magazine, 2002. [Online]. Available: http://www.chrisdendy.com/executive.htm.

[28] P. Luu and D. M. Tucker, "Self-regulation and the executive functions: Electrophysiological clues," The Cognitive Electrophysiology of Mind and Brain. Academic Press, 2003.

[29] A. R. Aron, "The neural basis of inhibition in cognitive control," The Neuroscientist, vol. 13, no. 3, pp. 214-228, 2007.

[30] R. M Roth, C. E. Lance, P. K. Isquith, A. S. Fischer, and P. R. Giancola "Confirmatory factor analysis of the behavior rating inventory of executive function-adult version in healthy adults and application to attentiondeficit/hyperactivity disorder," Archives of Clinical Neuropsychology, vol. 28, no. 5, pp. 425-434, 2013, doi: 10.1093/arclin/act031.

[31] S. Swami, "Executive functions and decision making: A managerial review," IIMB Management Review, vol. 25, no. 4, pp. 203-212, 2013, doi: 10.1016/j.iimb.2013.07.005.

[32] D. L. Zabelina, N. P. Friedman, and J. Andrews-Hanna, "Unity and diversity of executive functions in creativity," Consciousness and Cognition, vol. 68, pp. 47-56, 2019, doi: 10.1016/j.concog.2018.12.005.

[33] E. K. Miller and J. D. Cohen, "An integrative theory of prefrontal cortex function," Annual review of Neuroscience, vol. 24, no. 1, pp. 167-202, 2001, doi: 10.1146/annurev.neuro.24.1.167.

[34] P. D. Zelazo, U. Müller, D. Frye, and S. Marcovitch, "The development of executive function in early childhood: VI. The development of executive function: Cognitive complexity and control-revised," Monographs of the Society for Research in Child Development, vol. 68, no. 3, pp. 93-119, 2003.

[35] R. M. Roth, G. A. Gioia and P. K. Isquith, BRIEF-A: Behavior Rating Inventory of Executive Function--adult Version. Lutz, FL: Psychological Assessment Resources, 2005.

[36] P. K. Isquith, R. M. Roth, and G. Gioia. "Contribution of rating scales to the assessment of executive functions," Applied Neuropsychology: Child, vol. 2, no. 2, pp. 125-132, 2013

[37] D. Kirkpatrick and J. Kirkpatrick, Evaluating training programs: The four levels. Berrett-Koehler Publishers, 2006.

[38] R. E. Boyatzis, "The behavioral level of emotional intelligence and its measurement," Frontiers in Psychology, vol. 9, pp. 1-12, 2018, doi: 10.3389/fpsyg.2018.01438.

[39] R. E. Boyatzis, "When pulling to the negative emotional attractor is too much or not enough to inspire and sustain outstanding leadership," in The Fulfilling Workplace. Routledge, 2016, pp. 159-170.

[40] M. M. McClelland, et al., "Executive function, behavioral self-regulation, and social-emotional competence," Contemporary Perspectives on Social Learning in Early Childhood Education, vol. 1, pp. 113-137, 2007.

[41] A. R. Aron, "Progress in executive-function research: From tasks to functions to regions to networks," Current Directions in Psychological Science, vol. 17, no. 2, pp. 124-129, 2008, doi: 10.1111/j.1467-8721.2008.00561.x.

[42] L. Clark, et al., "Association between response inhibition and working memory in adult ADHD: a link to right frontal cortex pathology?" Biological Psychiatry, vol. 61, no. 12, pp. 1395-1401, 2007. 
[43] R. Bull, K. A. Espy and S. A. Wiebe, "Short-term memory, working memory, and executive functioning in preschoolers: Longitudinal predictors of mathematical achievement at age 7 years," Developmental Neuropsychology, vol. 33, no. 3, pp. 205-228, 2008, doi: 10.1080/87565640801982312.

[44] M. B. Denckla, "Research on executive function in a neurodevelopmental context: Application of clinical measures," Developmental neuropsychology, vol. 12, no. 1, pp. 5-15, 1996, doi: 10.1080/87565649609540637.

[45] J. Egeland and Ø. Fallmyr, "Confirmatory factor analysis of the Behavior Rating Inventory of Executive Function (BRIEF): Support for a distinction between emotional and behavioral regulation," Child Neuropsychology, vol. 16, no. 4, pp. 326-337, 2010.

[46] V. Stamenova and B. Levine, "Effectiveness of goal management training ${ }^{\circledR}$ in improving executive functions: A meta-analysis," Neuropsychological Rehabilitation, vol. 29, no. 10, pp. 1569-1599, 2018, doi: 10.1080/09602011.2018.1438294.

[47] A. Miyake and N. P. Friedman, "The nature and organization of individual differences in executive functions: Four general conclusions," Current Directions in Psychological Science, vol. 21, no. 1, pp. 8-14, 2012.

[48] A. Krasny-Pacini, M. Chevignard, and J. Evans, "Goal management training for rehabilitation of executive functions: A systematic review of effectivness in patients with acquired brain injury," Disability and Rehabilitation, vol. 36, no. 2, pp. 105-116, 2014, doi: 10.3109/09638288.2013.777807.

[49] A. Carmelli and A. Tishler, "The relative importance of the top management team's managerial skills," International Journal of Manpower, vol. 27, no. 1, pp. 9-36, 2006, doi: 10.1108/01437720610652817.

[50] D. Bakotić, "Relationship between job satisfaction and organisational performance," Economic ResearchEkonomska Istraživanja, vol. 29, no. 1, pp. 118-130, 2016, doi: 10.1080/1331677X.2016.1163946.

[51] T. Thomas, J. R. Schermerhorn Jr, and J. W. Dienhart, "Strategic leadership of ethical behavior in business," Academy of Management Perspectives, vol. 18, no. 2, pp. 56-66, 2004, doi: 10.5465/ame.2004.13837425.

[52] M. A. Runco and G. J. Jaeger, "The standard definition of creativity," Creativity Research Journal, vol. 24, no. 1, pp. 92-96, 2012, doi: 10.1080/10400419.2012.650092.

[53] A. Mehra, M. Kilduff and D. J. Brass, "The social networks of high and low self-monitors: Implications for workplace performance," Administrative Science Quarterly, vol. 46, no. 1, pp. 121-146, 2001.

[54] J. Oosterlaan, A. Scheres and J. A. Sergeant, "Which executive functioning deficits are associated with AD/HD, ODD/CD and comorbid AD/HD+ ODD/CD?” Journal of Abnormal Child Psychology, vol. 33, no. 1, pp. 69-85, 2005.

[55] D. Kahneman and A. Tversky, Choices, values, and frames. New York; Cambridge, UK: Russell Sage Foundation, 2000.

[56] C. Blair and A. Ursache, "A bidirectional model of executive functions and self-regulation," In K. D. Vohs and R. F. Baumeister, Eds., Handbook of self-regulation: Research, theory, and applications. Guilford Press, 2011, pp. 300-320.

[57] M. R. Ellefson, S. T. Baker, and J. L. Gibson, "Lessons for successful cognitive developmental science in educational settings: The case of executive functions," Journal of Cognition and Development, vol. 20, no. 2, pp. 253-277, 2019, doi: 10.1080/15248372.2018.1551219.

[58] S. Goldstein and J. A. Naglieri, Handbook of Executive Functioning. Springer-Verlag New York, 2014.

[59] W. Hofmann, B. J. Schmeichel, and A. D. Baddeley, "Executive functions and self-regulation," Trends in Cognitive Sciences, vol. 16, no. 3, pp. 174-180, 2012, doi: 10.1016/j.tics.2012.01.006.

[60] J. Liew, "Effortful control, executive functions, and education: Bringing self-regulatory and social-emotional competencies to the table," Child Development Perspectives, vol. 6, no. 2, pp. 105-111, 2012.

[61] T. Chen and D. Li. "The diversity of executive functions in normal adults: A latent variable analysis," Acta Psychologica Sinica, vol. 37, no. 02, pp. 210-217, 2005. 